\title{
Analysis on the Applicability of Multimedia Technology in the Teaching of Advanced Mathematics
}

\section{Zhu Huaihong, Nie Raorong}

Nanchang Institute of Science and Technology, Nanchang, China

Keywords: multimedia technology; advanced mathematics; teaching mode; applicability

\begin{abstract}
This paper starts from the limitations of traditional classroom teaching in new trend, explores the applicability of multimedia technology in the teaching of advanced mathematics, analyzes its disadvantages and discusses measures to make use of multimedia technology to assist the teaching of advanced mathematics.
\end{abstract}

\section{Limitations of Traditional Classroom Teaching in New Trend}

The teaching mode of traditional advanced mathematics has indeed played a major role in personnel training and knowledge transfer. However, with the development of technology and the reform of the teaching system, the traditional teaching model has not been applied to the current teaching of advanced mathematics with various limitations. Limitations on classroom information capacity, student number, classroom communication and interaction and different requirements are analyzed in detail.

\subsection{Limitation of classroom information capacity}

The current teaching content of advanced mathematics has gradually evolved from theoretical research to an applied research based on theoretical research, which requires classroom to provide classroom information capacity. At the same time, the setting of college curriculum directly causes the gradual reduction of advanced mathematics classes. With a large capacity and less class hours, the traditional teaching mode can only reduce the content of advanced mathematics to reduce course capacity.

\subsection{Limitation of student number}

In traditional teaching mode, the teaching is mainly based on the teacher's blackboard writing, which can effectively strengthen the effective communication between students and teachers. However, with the expanding enrollment of colleges and universities, the number of students learning advanced mathematics is increasing. At this time, traditional blackboard writing will inevitably directly affect the actual teaching effect. The number of students is limited to ensure that the teaching effect is not affected.

\subsection{Limitation of classroom communication and interaction}

In traditional teaching method, the communication between students and teachers is mainly through questioning, which has certain advantages in small class teaching. But if it is in a large class environment, this advantage cannot be sustained, which is mainly because in the large class environment, the mathematics level between students is uneven, the number of students is large, and teachers can't answer each question raised by each student, thus, the quality of teaching will inevitably decline.

\subsection{Limitation of different requirements}

For the learning of advanced mathematics, different students have different requirements. For example, there are requirement of major, the need of postgraduate entrance examinations, or the need of students' individualized learning. Therefore, the traditional teaching mode of advanced mathematics courses is inevitably unable to meet the different needs of different students. In 
addition, for most colleges and universities, the advanced mathematics is mainly set in the first year of college, and students at this stage cannot be clear about their own needs for advanced mathematics.

\section{The Applicability of Multimedia Technology in the Teaching of Advanced Mathematics}

With the development of science and technology, the application of multimedia technology in teaching has become an inevitable trend, which can also effectively avoid limitations of traditional classroom teaching in new trend. Advantages of multimedia technology in the teaching of advanced mathematics are analyzed in five aspects. Specifically, firstly, multimedia technology is the displaying tool in advanced mathematics teaching; secondly, multimedia technology is the presentation tool in advanced mathematics teaching; thirdly, multimedia technology can cultivate the application awareness of advanced mathematics; fourthly, multimedia technology provides favorable conditions for students' independent development; fifthly, multimedia technology can create a clean teaching environment.

\subsection{Multimedia technology is the displaying tool in advanced mathematics teaching.}

In the teaching of advanced mathematics, the amount of information is too large and a large amount of blackboard writing is required. At the same time, in addition to the need to teach relevant mathematics knowledge and application through blackboard writing, teachers need more blackboard writing to display related exercises and cases, which will inevitably waste a lot of classroom time. However, with the multimedia electronic blackboard, information can be made in the form of PPT in advance to display during class, which can effectively save class time and greatly improve teaching efficiency to a certain extent.

\subsection{Multimedia technology is the presentation tool in advanced mathematics teaching.}

As an abstract subject, the teaching of advanced mathematics is inevitably boring, which greatly increases the difficulty of students' learning. And the static teaching mode of traditional teaching reduces the effect of classroom teaching to a certain extent. At this time, with multimedia technology, dynamic teaching can be realized through a combination of sound, text, pictures, video, etc., and multimedia technology is the effective presentation tool.

\subsection{Multimedia technology can cultivate the application awareness of advanced mathematics.}

Higher mathematics is widely used in life and work, especially in engineering technology and economic statistics. The development of science and technology makes it difficult for students to understand the significance of learning advanced mathematics. Therefore, in the process of learning, they only learn relevant basic concepts of advanced mathematics, theorems, etc., do not have much understanding of the application of advanced mathematics. The application of multimedia technology in advanced mathematics teaching can make it easier to implement mathematics experiments and mathematical modeling. In this process, students' ability to apply advanced mathematics and solve problems can be significantly improved.

\subsection{Multimedia technology provides favorable conditions for students' independent development.}

The application of multimedia technology makes the teaching process no longer a one-off, but can be repeated. For instance, when a student's mathematics knowledge of one aspect is not well mastered, he can learn again by repeatedly watching the courseware, which to a certain extent, can enable students to learn more actively and provide favorable conditions for students' independent development.

\subsection{Multimedia technology can create a clean teaching environment.}

The blackboard writing in traditional teaching method will inevitably use a large amount of chalk, which will cause environmental pollution to a certain extent, directly damaging the health of 
teachers and students. However, multimedia technology can create a cleaner and healthier teaching environment.

\section{Disadvantages of Multimedia Technology in the Teaching of Advanced Mathematics}

The advantages of multimedia technology in the teaching of advanced mathematics are very wide, but everything has two sides. In this paper, the disadvantages of multimedia technology in the teaching of advanced mathematics are analyzed in six aspects, including the formalization of courseware making, the programmed teaching process, the excessive application of courseware, the large teaching capacity, the weakening thinking ability and the lack of emotional education.

\subsection{The formalization of courseware making}

In the teaching of advanced mathematics, the courseware is produced to better improve teaching efficiency and achieve teaching objectives. However, in actual teaching, many teachers add a lot of beautiful pictures and some sounds to the courseware in order to make the courseware look more beautiful, which leads to too much extra information in the courseware, directly influencing students' attention in teaching, and ultimately the teaching effect cannot be achieved.

\subsection{The programmed teaching process}

The teaching process of advanced mathematics should be a dynamic process. The teaching effect of the classroom can be improved by constantly adjusting their teaching status through the expression and reflection of students in the teaching process. When using multimedia technology in teaching, more teachers are sitting and showing PPT, and the rhythm of teaching is also according to PPT. Teachers can't adjust teaching behavior in time, which leads to the programmed teaching process.

\subsection{The excessive application of courseware}

The main feature of advanced mathematics is that not all content in the course can be expressed in the form of multimedia technology. However, some teachers rely heavily on multimedia technology in the teaching process for convenience, thus ignoring the actual teaching effect. At the same time, the teaching courseware used by teachers are sometimes courseware produced by others, and even downloaded directly from the Internet, which is seriously inconsistent with the actual teaching content.

\subsection{The large teaching capacity}

The application of multimedia technology in advanced mathematics teaching can effectively save a lot of time of blackboard writing, so the time saved will inevitably be applied to other aspects. Thus, in order to enrich the teaching content and reasonably use classroom time, some teachers add more exercises and even some mathematics knowledge beyond the students' cognition, which greatly aggravates the burden of students and is not conducive to the future learning of advanced mathematics.

\subsection{The weakening thinking ability}

The application of multimedia technology in advanced mathematics teaching can express the abstract mathematics knowledge more concretely, so that students can concentrate more on the learning process and understand and master the relevant mathematics knowledge more easily. However, it will directly weaken the students' mathematical thinking ability. In the long run, it is not conducive to the future study and future development of students' advanced mathematics knowledge.

\subsection{The lack of emotional education}

The traditional teaching method will waste a certain amount of time, but it will also deepen the communication between students and teachers. However, the application of multimedia technology 
in advanced mathematics teaching has directly caused that teachers become projectionist and lecturer, and there is very little communication with students, which will reduce the effectiveness of teaching to a certain extent, and will also result in the lack of emotional education for students, which will have a certain negative impact on students' future learning.

\section{Measures to Make Use of Multimedia Technology to Assist the Teaching of Advanced Mathematics}

At present, more and more colleges and universities use multimedia technology to carry out teaching. The application of multimedia technology in advanced mathematics teaching does bring a lot of advantages, but problems in the application of multimedia technology in advanced mathematics also exist. Therefore, in order to achieve better teaching effect, it is necessary to take corresponding measures to solve problems, including the combination of traditional teaching and multimedia teaching, the strengthening of teaching staff construction, the strengthening of leading role of teachers, the effective and diversified courseware making, the application of multimedia technology to focus on teaching key points.

\subsection{To combine traditional teaching and multimedia teaching}

Both the traditional teaching mode and the multimedia teaching mode have their own advantages and disadvantages. The simple use of a certain teaching mode will inevitably impact teaching results. Therefore, the combination of traditional teaching mode and multimedia teaching mode can be fully utilized to give full play to the advantages of these two teaching modes and ultimately achieve better teaching results. It should be noted that in multimedia technology teaching, multimedia technology is just a teaching method to assist the teaching to give full play to the benefits.

\subsection{To strengthen the construction of teaching staff}

The society is constantly developing, so the quality level of students will also be in continuous development. Therefore, teachers need to continue to learn before they can be eliminated by society. The application of multimedia technology in teaching is inevitable, and in order to achieve better teaching results, teachers need to continuously improve their own ability, so that they can better use multimedia technology and ultimately bring better teaching results.

\subsection{To strengthen the leading role of teachers}

In advanced mathematics teaching, teachers are always classroom organizer, controller and manager. Therefore, the leading role of teachers needs to be fully exerted, instead of multimedia courseware as the dominant one. Teachers make reasonable use of courseware and blackboard writing, better and efficient teaching will be reached. At the same time, in the teaching process, teachers also need to pay attention to the formation of personal style, so that students can be more actively involved in the teaching process, and ultimately achieve better teaching objectives. In addition, the communication between teachers and students in traditional teaching mode is very important.

\subsection{To make effective and diversified courseware}

In the application of multimedia technology in teaching, the production of courseware is very important. Generally speaking, the courseware shall be effective and diversified, so that it can make it play a role in teaching. And the production of courseware also needs to be based on the characteristics of advanced mathematics and psychological characteristics of students to pursue the simple and clear courseware and ensures that students can truly understand the content of the courseware.

\subsection{To make use of multimedia technology to focus on teaching key points}

The application of multimedia technology in practical teaching is always determined by the 
teaching content. As an auxiliary teaching method, multimedia technology can truly play the role of media technology only through the combination with teaching content. Besides, not all content of advanced mathematics can be taught through multimedia technology. Different teaching contents are taught in different ways, so that the actual effect of teaching can be truly improved.

\section{Conclusion}

In conclusion, multimedia technology can indeed play a certain role in advanced mathematics teaching, but it is impossible to teach just with multimedia technology, and the reason is related to the teaching content of advanced mathematics. This paper mainly analyzes the applicability of multimedia technology in the teaching of advanced mathematics, and analyzes the problems, and also proposes corresponding suggestions to provide reference for related personnel.

\section{References}

[1] Du Weiping. How to Cultivate Students' Interest in Learning Advanced Mathematics Learning by Multimedia Technology [J]. Electronic Test, 2013 (24).

[2] Zhang Binyan, Huo Benyao. Practice and Thinking on the Introduction of Multimedia Technology in Advanced Mathematics [J]. Education and Vocation, 2009 (27).

[3] Wang Yonglian, Wu Yongduan. A Universally Applicable Fatigue-Crack-Growth-Rate Description [J]. Acta Aeronautica ET Astronautica Sinica, 1987 (04).

[4] Sun Chaojuan, Meng Jieran. Research on the Applicability of Flipped Classroom Teaching in Colleges and Universities [J]. Chinese Character Culture, 2018 (05).

[5] Liu Shuqing, Zhang Gaizhi. Applicability Choice and Realization Condition of College Classroom Teaching Method [J]. Journal of Taiyuan Normal University (Social Science Edition), 2013 (02).

[6] Zhang Wenjing. The Necessity of Curriculum Reform of Advanced Mathematics [J]. Technology Outlook, 2015 (14).

[7] Xu Nannan. The Application of Multimedia Technology in College Calligraphy Demonstration Teaching [J]. Journal of Changchun Normal University (Natural Science), 2017 (12).

[8] Wang Suli. Research on Universal Type of Multimedia Technology and Application Course Teaching [J]. Computer Knowledge and Technology, 2016 (02).

[9] Gong Chang, Wang Wei, Jiang Haolin. Research on Teaching of Multimedia Technology Course in Colleges and Universities [J]. Education Forum, 2016 (36).

[10] Mullah Turghon. Teaching Research and Practical Exploration of Multimedia Technology and Application [J]. Asia Pacific Education, 2015 (30). 